\title{
To treat or not to treat: the legal, ethical and therapeutic implications of treatment refusal
}

\author{
A N Wear and D Brahams Senior Registrar in Psychiatry and Barrister at Law, respectively
}

\section{Authors' abstract}

Health professionals faced with refusal of life-saving treatment may wish to override a person's wishes, especially if that person suffers from a mental disorder.

Mental illness does not automatically mean a patient is incapable of making decisions of this nature. It is not always clear whether an individual is legally competent to decide whether to undergo treatment or not. This article discusses a clinical example and analyses some of the moral implications.

\section{Introduction}

Depressed patients may lack insight into their own condition which would enable them to make a valid informed treatment decision yet not be so disturbed that they can be regarded as totally lacking the capacity either to consent or refuse.

In this article we describe a patient who refused essential treatment. There existed grounds on which treatment could be enforced and equally persuasive grounds for respecting his wishes. The legal and ethical aspects of this dilemma are discussed and finally how the dilemma was resolved therapeutically.

\section{Case history}

MJ, a fifty-seven-year-old retired garage owner, was brought to a hospital out-patient department by friends (somewhat reluctantly) because his diabetes was poorly controlled. For eight weeks following the departure of his wife he had 'let himself go'. He no longer read the paper, he spent his days despondent because his wife did not return and occasionally he went looking for her. He stopped taking his oral hypoglycaemics and, a week prior to his referral, two toes on his left foot went black. The examining doctor recommended amputation of these toes, a procedure he flatly refused. He declined any in-patient treatment insisting that he be taken home. The doctor referred him to a liaison psychiatrist - suggesting that he had a depressive illness which prevented him from appreciating the seriousness of his condition.

\section{Key words}

Treatment refusal; mental competence; informed consent.

\section{Background}

$\mathrm{MJ}$ had lived in the area for many years. He never knew his father, but lived with his mother until she died. As a child he had a number of neurotic traits including encopresis and school refusal. He was educated and left school at sixteen to work in the car trade. He was successful in this, eventually owning his own garage. He developed diabetes in his late forties, and despite treatment, ocular complications. He was sighted, and in spite of his illness led a full life. He had no children or other dependants from his ten-year marriage. His wife left following a row in the context of an already dependent and 'clinging' relationship.

His mental state reflected much of this recent tragedy although he was alert, co-operative and orientated. He complained of disturbed sleep, loss of interest, self-blame and general self-neglect. He was not suicidal, but merely wanted to be left alone - not to die, but he would rather not be bothered by all the fuss.

His appraisal of his condition was accurate. He recognised that the toes of his foot were gangrenous and knew that this would worsen if untreated. He was tired, fed up and simply did not want the offered treatment. He accepted that he might die, but recognised that this would not be immediate. (He had dry gangrene of the toes and it was estimated that he would be septacaemic in forty-eight hours.)

The clinical impression was of a man with much to be depressed about. His wife had left him, he found coping (without her) very difficult. He had a chronic disease. He was suffering from a depressive illness and, in refusing the offered treatment was at risk of dying.

The question for clinical management was whether he was to be detained under the Mental Health Act to allow treatment of his mental state (and coincidentally any physical complications of this), or whether his refusal of treatment was 'informed' and he was capable of making this judgement.

In practical terms, obtaining a second opinion by asking relatives or friends for their views provides additional information and probably reduces the chances of legal complications. However, the underlying uncertainties of informed consent and enforced treatment persist.

Consent to treatment has recently been re-examined 
and consent procedures in the National Health Service clarified. Consent to a physical procedure by a patient must be informed, voluntary and be made by a person competent to make such a decision (1). Similarly a refusal of 'essential' medical treatment needs to be informed, voluntary and made by someone with the capacity to make such a decision. A recent legal case from Massachusetts supported this view, ruling that a committed mental patient could justifiably refuse treatment unless adjudicated incompetent by a judge (2).

\section{Legal considerations}

In England a patient must give his or her consent (express or implied) to medical treatment. Parents of children can consent on their behalf, though statute provides that at 16 and over, the child can give valid consent to all medical and dental treatment. Depending on his intelligence and maturity, a child below the age of 16 may also legally consent to treatment. Where parents are perceived as failing to act in the child's best interests, (for example refusal of blood transfusion where necessary), the doctor (in an emergency) may ignore the parents' refusal though where time permits, the child should be made a ward of court.

Sterilisation of mentally incapable minors will always require the court's permission where the purpose is social rather than immediately medically indicated.

Other exceptions to the general principle of consent made are emergencies, where consent may be deemed, provided there is no clear indication to the contrary. In the case of mentally incapable adults, where the treatment is for mental illness the Mental Health Act authorises medical intervention in certain circumstances, however where the treatment is for a purely physical condition, it does not apply (3). For some years there was left an apparent lacuna in the law with regard to mentally incapable adults as relatives may not lawfully consent to treatment on their behalf. The position was finally resolved by the House of Lords in the case In re $F(4)$, which allows a doctor to carry out such treatment as he or she feels is required in the patient's best interests. He or she must act in a manner thought competent and reasonable by a responsible body of medical opinion and it will usually be sensible to get a second opinion and consult with the family before intervening, particularly if the patient seems reluctant and/or the treatment is in any way controversial. The court's consent to sterilisation should normally be sought if contraception is not the prime purpose of the operation or it is an incidental effect of a necessary procedure, for example hysterectomy.

Though these principles may be stated with a fair degree of clarity, in everyday clinical practice it is not always easy to decide whether an otherwise lucid adult who is deeply depressed has the insight and judgement to enable him to give a valid consent to treatment. His judgement and ability to see things in perspective mays. seem impaired or distorted to the doctor, but the question is, is his mental capacity so impaired that the doctor is entitled to override a decision to refuse? treatment. The doctor is not as of right entitled to substitute his decision for that of the patient simply because he does not agree with it even if the outcomes will be death. He will have to be sure on clinicab grounds that the patient lacks the necessary capacity top make an informed decision, at least at the relevant time. If the patient's mental condition is likely to improve to a point where he can make an informe $\bar{\omega}_{\omega}$ decision, wherever possible the doctor must hold hise hand and wait for it to be forthcoming. Of course there may be situations where there is very little time left for manoeuvre and where undue delay will render $N$ treatment ineffective and/or during which the patient's $\mathrm{s}$ condition is certain to deteriorate even to the poine where he may die. The law has never pretended to beo watertight and grey areas leave doctors free to make clinical decisions that may later be challenged in court. $c)$

\section{Ethical considerations}

By and large doctors (and other health professionals are more likely to be guided in their decision-making by conscience (or what seems to them to be the righte course) than by any legal constraints. In dischargig that duty (or exercising clinical freedom) there emerge conflicting moral principles. Four moral perspectitis can be applied in this example:

1) Rights theory: All living people have rights. Thesê⿸ rights include the right to medical treatment, the righ? to be resuscitated when unconscious and the right to doㄹ what they want within the limitation that it does not interfere with another person's rights. The conflic兵 here arises with the patient's refusal of treatment (his. right) versus the right of others to give treatment when deemed necessary by a doctor. In this perspective the issue of overruling rights rests on whether a person's]. opinion is expressed when he is competent to formo such an opinion.

2) Virtue theory: Virtuousness is the desirable quality - that is the fair person is the moral champion. In this perspective to be fair means making a just decisiono (though what this is remains unknown until a court has ruled). The conflict here arises because being fair mayos not be doing good, ie making the sick person well $N$ Benevolent action by the doctor may not be virtuous. N 3) Commonsense morality: This refers to something we are all familiar with. Its origins are within ourselves and amount to a moral perspective we have been? brought up with. In this example the conflict arisesf between beneficence and autonomy. It is, in this paradigm, wrong to go against somebody's wishes. As with the Rights theory, the question of competenced arises. Is this person competent to make requestsक्ण which could be interpreted as his right?

4) Utilitarianism: This perspective stresses outcome.? Providing that the result increases welfare (or is 
morally desirable) then the means should be considered less important. In other words some pain or discomfort is justified in treating a condition providing the result increases welfare. In medicine much is done basing argument on a utilitarian view including unpleasant treatments for leukaemia or disfiguring surgery for breast cancer. However, in defining welfare one must be cautious because a desirable aspect of eventual welfare is the right to be able to refuse certain treatments.

Within these paradigms, conflicting and coinciding, are four moral principles:

Beneficence - the desire to do what is considered best for a person. This includes paternalism as there are occasions where an individual cannot appreciate his best course.

Autonomy - the fundamental right that people have to choose their own destiny. Autonomy conflicts with beneficence and from this a moral dilemma emerges.

Justice - the principle that values fairness and consistency. It is probably a mistake to confuse this form of justice with the justice administered by the courts. In theory, of course, a just course would be endorsed in law.

Non-maleficence - the fundamental principle of 'first do no harm'. In other words a course that is taken that may go wrong or does not promote welfare is unacceptable. Short-term harm has to be weighed with long-term gains.

In treating this man two questions arise. Firstly is the intended treatment - the removal of his toes - justified? And secondly can it be done against his wishes?

The first question is easier to answer and lies in the realm of medical expertise. Knowledge acquired from experience and by scientific research can present a persuasive argument that such a treatment is justified to prevent septacaemia and death, though its implementation is not without risk and discomfort.

The second question is more difficult and belongs to another (non-medical) field of expertise. It is this area that psychiatry (despite its strong links with physical medicine) is sometimes thought to champion. Psychiatrists being those doctors who 'understand' these things!

In addressing this dilemma the question of competence emerges. On the whole many would accept treatment refusal if they believed it was informed, voluntary and made by someone who is competent.

\section{How much autonomy?}

J S Mill, in his essay, On Liberty, acknowledged that incompetent individuals did exist. Children and those suffering from 'backward states' needed guidance; if unrestrained, he anticipated the emergence of chaos. Even the most Libertarian view of autonomy would acknowledge situations where autonomy could be overridden. What is unclear is how these judgements are made. There are two ethical models that assist in assessing an individual's ability to act autonomously. [The capacity to be autonomous is sometimes referred to as competency - that is competence to make particular choices.]

Competence is a property of an individual determined by a personal normative standard. In other words it is a value judgement that varies from moment to moment and situation to situation. One simple view would be for a minimum standard or threshold above which an individual could be considered to be competent. Those falling below would be guided, those above, free to choose regardless of the consequences. An example of this is in evidencing a choice (5). If a person knows he has a choice to make then this can be taken as the minimum standard of mental functioning required to make that choice. An attraction of this minimum standard is its consistency and ease of application. Its limitations are its invalidity. As a test it may test for something but it is not the capacity to act autonomously.

A more acceptable model requires a balance between the decision that has to be made and an individual's capacity to make it (6). An important decision such as the refusing of a life-saving operation has to be balanced with the mental competence of the person making it. This model's advantage is that it avoids becoming limited to one aspect of the problem. For MJ the question is not, is he suffering from a mental disorder that renders him incompetent? Instead the question is, does he fully understand what refusing to have the operation means or is his refusal part of a depressive desire for death?

Although this latter question may be unanswerable it can guide questioning so that some understanding of the refusal to co-operate with treatment is acquired. In this example part of the refusal may have been a desire to involve his next of kin (his estranged wife); there may have been a hope that refusing treatment would have engineered her return.

Clearly this can only be determined through establishing a relationship with the patient based on trust and honest disclosure. This aspect of the professional relationship - based on the fiduciary principle - is paramount in assessing the ability to decide autonomously. Furthermore, through the partnership process persuasion can influence the decision. This process will of course take time and is often successful in making a person re-appraise his or her decision. Its value should not be underrated.

\section{A test for competency?}

Competence is a legal judgement. In English law fitness to plead and testamentary capacity are both forms of mental competence. The court requires certain mental abilities of the accused (in the case of fitness to plead) so that it is satisfied he understands the proceedings. These legal guidelines can then be enacted by psychiatrists making the assessment of that 
person's ability to plead. As such they are exceedingly useful.

In the United States, the right to refuse treatment has received more attention. One writer (7) has specifically addressed the question of competence in relation to treatment refusal. He suggests the following factors in assessing competence:

- The patient's knowledge that he has a choice to make.

- The patient's ability to understand the available options and their advantages and disadvantages.

- The patient's cognitive capacity.

- The absence of any interfering pathological perception or belief, such as a delusional system surrounding the decision.

- The absence of any interfering emotional state, such as severe depression or euphoria.

- The absence of any interfering motivational pressure such as pathological rage.

- The absence of any interfering pathological relationship such as the conviction of helpless dependency on another person.

- An awareness of how others view the decision and the general societal attitude towards the choices, and an understanding of his reasons for deviating from that attitude if he does so.

This casuistic approach demonstrates how cumbersome a test could become. Such high standards may lead to a large number of otherwise socially competent people being declared incompetent in the face of a treatment refusal. It's interesting to note that using these standards $\mathrm{MJ}$ was incapable of making an informed choice and as a consequence might 'justifiably' have been treated against his wishes.

Another less stringent approach looks at mental capacities. Three possible capacities for competency are:

1. The ability to understand and communicate. These include the capacity of a person to become informed and to express his choice for treatment.

2. The ability to reason and deliberate. A more complex function which allows an individual to consider information and draw inferences about making certain choices. Short-term memory is considered essential for this process.

3. A set of values or conception of what is 'good' which has been stable over time and with which the individual's eventual choice is minimally consistent (8).

Clinical situations in which a dilemma occurs can lead to profound disagreements within a team. Arguments over capacities to decide need to focus on particular areas. In our case the first two capacities are probably present but the dilemma arises in relation to the third: Is this how $\mathrm{MJ}$ always considered surgery and has he always seen the development of gangrene as the time when he wanted to stop living?

Any enquiry after the event is likely to be biased as opinions polarise with the exigency of the situation. $A \Rightarrow$ further problem arises in asking the carers concerned $\stackrel{5}{?}$ to accept a decision: Suppose a standard of competency $\bar{C}$ is met, could we live with the therapeutic decision this $\frac{\overline{\bar{n}}}{\mathrm{n}}$ binds us to?

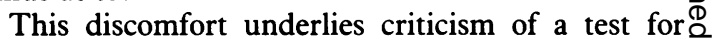
competence. Any test needs to be valid and reliable. At $\cong$ present there is no yardstick to assess these functions. $\vec{D}$

This is Sir Douglas Black's view (9). Guidelines, he $\cdot$ suggests, lead to restrictive and inflexible practice; at $\vec{\omega}$ worst a checklist which abrogates a doctor from his professional responsibilities, at best a limitation on allowing a doctor to practise his art in an 'ethically ${ }_{-}$ aware' manner. This argument is persuasive. The clinician faced with the dilemma described above must make difficult choices; these dilemmas are frequent $\stackrel{\omega}{\omega}$ and as professionals we should be able to shoulder theo responsibilities but, he adds, we have a right to know why these problems are difficult. A strong advocate forcs ethical education, he makes this, at the present time, a $\mathbb{D}$ more attractive route. But it hangs in the balance. If $\overrightarrow{\mathbb{D}}$ doctors bow to the pressure of defensive medicine, then a test for competency will soon become necessary. For now we act according to moral principles $\overrightarrow{0}$ inculcated through experience and education.

\section{Therapeutic outcome}

In deciding not to enforce treatment wide consultation was undertaken. It was felt that $\mathrm{MJ}$ was able to understand the consequences of refusing treatment $\frac{}{\mathbb{Q}}$ even if his argument for not being treated was difficult $\stackrel{\varrho}{\rightleftharpoons}$ to see. Having decided this a therapeutic relationship was maintained by offering further care outside the hospital. (It is worth noting that rejection of therapeutic endeavours are sometimes taken personally by a doctor, resulting in a rejection of further care for the patient.)

The following day MJ agreed to come back to 3 . hospital where he underwent a surgical operation. Heס left hospital six weeks later, considerably improved both mentally and physically.

\section{Conclusion}

A clinical example in which autonomy was respected and treatment was eventually implemented is far easier $\tilde{N}$ to report than if in respecting autonomy the patient hadn died. It does however highlight how moral priciplesN influence medical practice and decision-making. In $_{\sigma}^{\omega}$ these situations a course of action rather than the tradition of diagnosis and treatment becomes? paramount. Doctors, through their training, often $\mathbb{D}^{+}$ have a well-defined sense of making the correct choices. Sometimes, there is no correct choice. $\mathrm{MJ}_{0}^{-}$ could have easily been prevailed upon to undergoه treatment if he had met a different collection of medical $\frac{\stackrel{\oplus}{\oplus}}{\sigma}$ advisers, and the outcome would have been identical. ㅇ

But who should make these decisions? Doctors or lawyers, casuistry or sophistry? An ethically educated 
view is preferable to blind paternalism. More recently an advocacy system has been suggested whereby a person's decision, where it conflicts with the doctor's can be represented by an advocate to argue his point of view. This does offer a mechanism for resolving such dilemmas but the decisions are likely to remain as vexed as ever.

\section{Acknowledgement}

We would like to thank Dr K W M Fulford for his advice in preparing the manuscript.

$\operatorname{Dr} A N$ Wear is a Senior Registrar in General Psychiatry at Cavendish House Community Mental Health Centre, Portsmouth. He is a member of the Royal College of Psychiatrists. Mrs D Brahams is a Barrister at Law, practising in Lincoln's Inn. She is Editor of the Medicolegal Journal, Legal Correspondent to the Lancet and a Fellow of the Royal Society of Medicine.

\section{References}

(1) Dyer A R, Bloch S. Informed consent and the psychiatric patient. Fournal of medical ethics 1987; 13: 12-16.

(2) Gutheil T G, Rogers V. Commissioner - denouncement of an important right-to-refuse treatment case. American journal of psychiatry 1985: 142, 2: 213-216.

(3) Department of Health and Welsh Office. Code of practice. Mental Health Act 1983. London: HMSO, 1989: Ch 15: 52-57.

(4) Brahams D. Sterilisation of mentally incapable woman. Lancet 1989 Jun 3: 1275.

(5) Roth L H, Meisal J, Lidz C W. American journal of psychiatry 1977; 134: 279-284.

(6) Eastman N L G, Hope R A. The ethics of enforced medical treatment - the balance model. Fournal of applied philosophy 1988; 5, 1: 49-59.

(7) Michels R. Competence to refuse treatment. In: Doudera A E, Swazey J P, eds. Refusing treatment in mental health institutions: values in conflict. Ann Arbor, Michigan: Aupha Press, 1982.

(8) Buchanon A E, Brock D W. Deciding for others. The ethics of surrogate decision-making. Cambridge: Cambridge University Press, 1989: 23-25.

(9) Black D. Guidelines or gumption? The role of medical responsibility: a view from the profession. In: Hirsch S R, Harris J, eds. Consent and the incompetent patient - ethics, law and medicine. London: Royal College of Psychiatry, 1986: 29-31. 